NBER WORKING PAPERS SERIES

INTERNATIONAL TRADE WITH ENDOGENOUS TECHNOLOGICAL CHANGE

Luis A. Rivera-Batiz

Paul M. Romer

Working Paper No. 3594

NATIONAL BUREAU OF ECONOMIC RESEARCH

1050 Massachusetts Avenue

Cambridge, MA 02138

January 1991

We have benefitted from several conversations with Gene Grossman and Elhanan Helpman about their work on related issues. Comments from Ray Riezman, Robert staiger and Danyang Xie were also very helpful. The work of the second author was supported by NSF grant \#SES88-22052, by a sloan Foundation Fellowship, and by the Center for Advanced Studies in the Behavioral Sciences, which received support from NSF grant \#BNS87-00864. This paper is part of NBER's research program in Economic Fluctuations, Growth, and Financial Markets and Monetary Economics. Any opinions expressed are those of the authors and not those of the National Bureau of Economic Research. 
NBER Working Paper \#3594

January 1991

\section{INTERNATIONAL TRADE WITH ENDOGENOUS TECHNOLOGICAL CHANGE}

\section{ABSTRACT}

To explain why trade restrictions sometimes speed up worldwide growth and sometimes slow it down, we exploit an analogy with the theory of consumer behavior. Substitution effects make demand curves slope down, but income effects can increase or decrease the slope, and can sometimes overwhelm the substitution effect. We decompose changes in the worldwide growth rate into two effects (integration and redundancy) that unambiguously slow down growth, and a third effect (allocation) that can either speed it up or slow it down. We study two types of trade restrictions to illustrate the use of this decomposition. The first is across the board restrictions on traded goods in an otherwise perfect market. The second is selective protection of knowledge-intensive goods in a world with imperfect intellectual property rights. In both examples, we show that for trade between similar regions such as Europe and North America, the first two effects dominate; starting from free trade, restrictions unambiguously reduce worldwide growth.

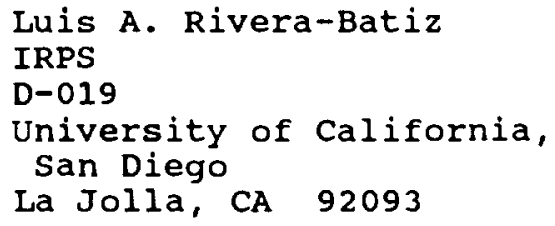

Paul M. Romer NBER

204 Junipero Serra Blvd. Stanford, CA 94305-8091 
In a model of endogenous growth with increasing returns, one of us (Romer, 1990b) showed that a reduction in the extent of the market brought about by trade restrictions leads to a decrease in the worldwide rate of growth. Using essentially the same model of growth, Grossman and Helpman (1990) showed that in some circumstances, trade restrictions could nevertheless increase the worldwide rate of growth.

In this paper, we relate these apparently contradictory results by using a decomposition of the change in the growth rate that is similar to the decomposition of a change in demand into a substitution effect that can be signed based on a priori reasoning and an income effect that cannot. We identify two effects of trade restrictions, which we label the integration effect and the redundancy effect, that unambiguously decrease worldwide growth rates. We identify a third effect of trade, the allocation effect, that can either increase or decrease the rate of growth.

We use a model with two fundamental sectors: a research and development sector that produces the new ideas that make continued growth possible, and a manufacturing sector that makes use of these ideas and produces physical capital and consumption goods. Output from each of these sectors can be described in terms of a reduced form equation that depends on basic inputs such as physical capital, human capital, and labor used in the sector. The allocation effect refers to changes sectorial output induced by changes in the allocation of basic inputs between the sectors. After trade opens, each country reallocates resources toward the sector in which it has a comparative advantage. As is clear from the classical theory of trade, allocation effects will be larger when the differences in the endowments or technologies of two trading partners are large.

In contrast to allocation effects, which link different sectors in the same country, integration effects link the same sector in different countries. Trade induces integration effects in a sector if its reduced form equation exhibits increasing returns. Increasing returns at the level of the sector could be associated with external effects arising from knowledge spillovers or with monopolistic competition between firms that supply a diverse 
set of specialized inputs used in production in the sector. If they are present, worldwide output from this sector will be larger when the two national sectors are integrated.

Trade restrictions will have a redundancy effect if they induce redundant research effort. When we measure the integration effect, we take as given the set of specialized inputs and pieces of knowledge available in each country. We ask merely whether output increases as the existing inputs and ideas flow more easily between the two countries. Redundancy is an inherently dynamic effect. Since the set of goods and ideas are growing over time, closer economic ties between nations can influence the new inputs and ideas that are produced. Redundancy occurs when the same specialized input or idea is invented or discovered twice, once in each country.

The integration or redundancy effects are defined holding constant the allocation of basic inputs between the manufacturing and research sectors, so it is possible to talk of an effect that takes place in one sector only. By definition, redundancy occurs only in the research sector. Since trade restrictions impede the exploitation of international increasing returns and since both integration and redundancy effects arise from increasing returns, both effects have unambiguously negative effects on output. Through its action in the manufacturing sector, the integration effect of trade restrictions decreases the level of income. Through their action in the research sector, both integration and redundancy effects decrease the rate of growth.

Since allocation effects link the manufacturing and research sectors, allocation effects always induce offsetting changes in the output of the sectors. If resources are shifted into manufacturing, they are shifted out of research. Hence, if the allocation effects of trade restricions have a positive level effect, they have a negative growth effect. Moreover, there are no simple conditions that characterize which sector gains resources when trade policy is changed. In general, allocation effects can increase or decrease the rate of growth.

With these informal definitions, the apparent conflict between the results described in the beginning can be resolved. In the thought experiment undertaken in the first paper 
(Romer 1990b), the trading partners are identical, so the allocation effect of trade is small, and in fact tends to reinforce the integration and redundancy effects. Trade restrictions between identical nations unambiguously decrease the worldwide rate of growth. In the experiment carried out by Grossman and Helpman (1990), trading partners have different technologies, so the allocation effect can be large. As they show, it can overwhelm the other effects. Growth can therefore speedup when trade restrictions are imposed.

To illustrate the use of our decomposition, we study two specific examples of trade restrictions. These examples extend the analysis of trade between identical nations. Our decision to focus on identical countries was guided partly by the belief that the decomposition is easier to grasp in this context. It applies, nonetheless, in all settings. Our decision also reflects the division of labor in research. To get a comprehensive picture of trade and growth, readers should also consult the growing literature on the growth effects of trade between asymmetrical countries, e.g. Dinopoulos, Oehmke, and Segerstrom (1990), Feenstra (1990), Grossman and Helpman (1989a, 1989b ,1989c ,1989d), Lucas (1988), Segerstrom, Anat and Dinopoulos (1990), and Young (1990).

In our first example, trade restrictions take the form of an across the board tariff, and we focus on allocation effects. One of the surprising results is that allocation effects can be present at all in the context of trade between countries with identical technologies and endowments. Beside showing why this is so, this example illustrates the ambiguity of the connection between allocation effects and growth. Starting from the point where the tariff equals zero, the growth rate decreases as the tariff rate increases. As the tariff continues to increase, the growth rate reaches a minimum, and then begins to increase. In our example, the growth rate does not, however, return all the way back to the free trade growth rate. (See figure 3 below for a plot of the growth rate as a function of the tariff rate.)

In our second example, we consider selective protection of specific goods in a world in which intellectual property rights are less then perfect. This lets us consider the 
simultaneous effects of reallocation and redundancy. To keep the length of paper manageable, we focus only on these two effects. In a companion paper, (Rivera-Batiz and Romer, 1991) we concentrate on the integration effect, with special emphasis on its action in the research sector that is the engine of growth.

Our examples in both papers were chosen primarily with a view toward illustrating the decomposition that we propose into allocation, integration, and redundancy effects. The strong conclusions that emerge from these examples are nevertheless of some interest in their own right. Taken together, our two papers show that there is a strong presumption that trade restrictions between similar regions like North America and Europe will reduce worldwide rates of growth.

The structure of the paper is as follows. In section 2, we describe a generic two sector model of endogenous growth that can be used to define scale, redundancy and allocation effects more formally. Section 3 then presents the specific model of endogenous growth that is used in this paper. Sections 4 and 5 present the two main examples. A conclusion summarizes the results and describes limitations and extensions. Detailed algebraic calculations are presented in an Appendix.

\section{Scale, Allocation, and Redundancy}

Before delving into the specifics of the model considered here, it is useful to describe integration, allocation and redundancy effects in a more general context. Consider the following representation of a growth model. Suppose that there are two broad sectors in the economy. The growth sector produces the input that makes sustained growth possible. In the model presented below, we refer to this input as the state of the technology and denote it by the letter $\boldsymbol{\Lambda}$. We call the sector that produces $\boldsymbol{L}$ the R\&D sector. Other models give a different interpretation to the input that sustains growth (e.g. a special form 
of capital or education) and to the sector that produces it, but the two sector structure of these models is similar to the structure we consider here.

The second sector in our generic model behaves like the neoclassical growth model. It makes use of $\$$ and produces all tangible goods such as consumption goods and physical capital. We need a name for this sector, and it is convenient to refer to this sector as the manufacturing sector, in a very broad sense of the term. It includes all activities in the economy other than $\mathrm{R} \& \mathrm{D}$.

The usual formulation of the neoclassical model describes output $Y$ as a function of capital $I$, labor $L$, and the state of the technology $d$. We distinguish human capital $B$ from labor $L$ and add it to the list of inputs because we assume that research is relatively human capital intensive and that manufacturing is relatively labor and physical capital intensive. Using a subscript $Y$ to denote inputs that are used in the sector that produces physical goods, we can write output $Y$ as

$$
Y=\mathcal{C}+\dot{I}=F\left(B_{Y}, L_{\gamma}, I_{Y}, \mathbb{A}\right)
$$

As in the usual one sector formulation, manufacturing output $Y$ can be split between consumption $\mathcal{C}$ and increases in the capital stock $i$.

Output in the R\&D sector can be written as

$$
\dot{i}=\boldsymbol{R}\left(\boldsymbol{B}_{d}, L_{d}, I_{d}, d\right)
$$

The mnemonic here is $P$ for research. The subscript $A$ denotes the inputs devoted to the research sector, which produces increases in the stock of 1 . In both equations (1) and

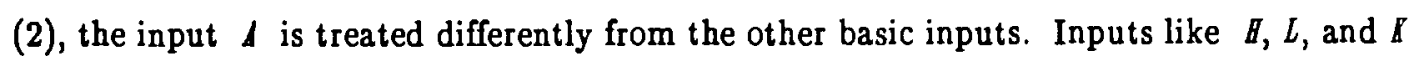
are rivalrous. They can be used in only one sector at a time. In contrast, the knowledge 
represented by $\Delta$ is nonrival. No subscript on $\Delta$ is necessary because the entire stock of knowledge represented by $\downarrow$ can be used in both sectors at the same time.

As noted in the introduction, we allow for the possibility of increasing returns in both of the reduced form equations (1) and (2). How integration between the same sector in different countries is achieved depends on the way in which sector-wide increasing returns are supported in a decentralized equilibrium with many firms. We consider two alternatives. The increasing returns could be purely external, arising from knowledge spillovers. In this case, closer integration between firms in the same sector and in different nations is achieved by international flows of ideas. Alternatively, the basic inputs could be connected to the final sectorial output through a large set of specialized activities and intermediate inputs that are provided by monopolistically competitive firms. In this case, integration is achieved by permitting flows of the intermediate inputs between the countries. In either case, if the reduced form equation for the sector exhibits increasing returns, the combined output of all firms in the sector will fall when the flow of ideas or intermediate inputs between the two countries is limited by trade restrictions, and will reach a minimum when the sector in one country operates in isolation from the other.

We assume that there are increasing returns with knowledge spillovers in the R\&D sector, and increasing returns with specialized inputs in the manufacturing sector. This means that the degree of integration in the manufacturing sector is determined solely by trade in specialized inputs in production. In the research sector, it is the process of communication of ideas, as fostered by telecommunications networks, printed media, international travel, study, and investment by multinational corporations that determines the degree of integration.

This strict separation is convenient and captures what we think are the most important effects in these different sectors, but it paints a stylized picture that is too simple. Knowledge spillovers are doubtless important in manufacturing, and anyone who has ever seen a laboratory knows that a vast number of specialized inputs are used in 
research. The formal model can be extended to take account of the world where both mechanisms are present in both sectors. For example, in the companion paper, we use a model with specialized inputs in both $R \& D$ and manufacturing (Rivera-Batiz and Romer, 1991). Devoting too much attention to how increasing returns are decentralized would, however, detract from one of the basic points of our analysis: it is the presence of sectorwide increasing returns that generates integration effects. How the increasing returns are decentralized is of secondary importance.

The three channels through which trade policy can affect the rate of growth are most clearly distinguished if one contrasts the extremes of total isolation and complete integration into a single economy. Let $z_{Y}$ and $z_{\mathcal{A}}$ represent the vectors of inputs used in manufacturing and R\&D respectively. With total isolation between two identical economies, worldwide manufacturing output is twice the output in each country, $2 Y=2 F\left(Z_{Y}\right)$. If the reduced form function $F(\cdot)$ exhibits increasing returns because of the underlying specialized intermediate goods that make use of the nonrival input $\mathbf{A}$, integration will increase worldwide output. (For a discussion of why nonrival inputs induce increasing returns, see Romer 1990a). In the definition of a pure integration effect, we assume that the split between $z_{Y}$ and $z_{A}$ in each country is held constant. Integration would cause worldwide manufacturing output to increase from $2 F\left(Z_{Y}\right)$ to $F\left(2 Z_{\gamma}\right)$. This is the integration effect in manufacturing. It increases the level of output associated with any given value of 4 , but it does not affect the rate of growth of 4 . Thus we say that the integration effect in manufacturing has a level effect but no growth effect.

When two research sectors operate in isolation using inputs $Z_{d}$, worldwide research output can lie anywhere in the interval between $\boldsymbol{P}\left(Z_{\mathbb{A}}\right)$ and $2 \boldsymbol{P}\left(Z_{\mathbb{A}}\right)$. The advantage of a nonrival good like an idea is that once it has been produced, it can be used by everyone in the world. This means that there is no economic value to devoting resources to produce the idea again if it already exists somewhere else. When resources are used to produce a design idea that already exists, the worldwide stock of 1 does not increase. If the two 
R\&D sectors operating in isolation produce solutions to exactly the same problems, then total worldwide production of $\$$ will be exactly equal to the production in either country, $P\left(z_{1}\right)$. If, on the other hand, there is no redundant research effort, worldwide research output will be twice that in either country, $2 R\left(Z_{\downarrow}\right)$.

As a result, when two isolated research sectors become more closely linked, worldwide research output can increase for two reasons. First, redundancy can be reduced or eliminated. The communication links and competitive pressures induced by closer ties will create incentives to avoid rediscovering the wheel. This is what we call the redundancy effect. Second, if there are increasing returns in the R\&D sector, then even if there is no redundancy, integration will increase research output from $2 R\left(Z_{A}\right)$ to $R\left(2 Z_{A}\right)$. This is the integration effect in the $R \& D$ sector.

The analysis of any change in policy toward other nations can therefore be separated into three conceptual steps. The first step is to hold constant the degree of integration of the two economies (that is, hold constant any constraints on flows of existing goods, services, and ideas) and to hold constant the allocation of resources between the different sectors in each economy. Then one can observe the degree to which firms and individuals reduce the degree of redundancy in their innovative activities in anticipation of increased future flows of goods, services, and ideas. Thus for example, an announced plan to open trade in goods (say in the near future) could induce a firm to stop trying to produce copies of goods available abroad and to start producing some unique specialized input. This isolates the redundancy effect of the policy change. By definition, it arises only in the research sector.

Next, the degree of integration between the different sectors is permitted to change as additional flows of existing goods and ideas take place. As ideas flow more readily between the two national research sectors and as firms take advantage of greater diversity in specialized inputs in manufacturing, the integration effects increase output in each sector. For example, integration could take place as an existing idea previously known 
only to researchers in one country becomes available for use in the second country.

Alternatively, integration could increase because an existing piece of specialized equipment that previously had been used in manufacturing in only one country becomes available for use in the second. At this stage we are still holding constant the stock of basic inputs in the two different sectors in the two economies.

Finally, in the last step, it is possible to compare the rate of return to the different basic inputs in the two sectors. These will generally not be equal after the change in trade policy, and it is then possible to analyze the allocation effect - the reallocation of inputs needed to bring rates of return back into equality.

The functions $F(\cdot)$ and $P(\cdot)$ described in this section are reduced form expressions for manufacturing and research output as functions of the amounts of the basic inputs devoted to each sector. The next section describes structural production functions and the market arrangements that lead to reduced forms of this kind. For a heuristic comparison of isolation and complete integration, reduced form expressions are sufficient; but to characterize the intermediate degree of integration induced by policies like across the board tariffs or selective protection, a structural specification is required.

\section{Specification of the model}

\subsection{Functional forms in the manufacturing sector}

The detailed structure of the production technology for the manufacturing sector is taken from Romer (1990b). The fundamental assumptions are that many types of capital goods are used in production, that these are not perfect substitutes, and that technological progress arises from the invention of new types of capital goods. To formalize this, let $i$ index the different types of capital goods and let $x(i)$ denote the usage of each type of 
good. Producers of consumption or capital goods face a production function of the form

$$
Y={B^{\alpha}}^{\alpha} L^{\beta} \int_{0}^{\Phi} x(i)^{1-a-\beta} d i
$$

This production function is homogeneous of degree 1 in $\|, L$, and the list of durables $x(i)$. Firms in this sector can therefore be assumed to be price takers. This production function has the feature that it is possible to produce output even if $x(i)$ is equal to 0 for many goods $i$. At every date, there are many durables that are potentially usable but that cannot be used because they have not been invented yet. Good $i$ has been invented if $i \leq \mathbb{A}$. Hence, the upper limit of integration can be changed from $w$ to $d(t)$ at each date $t$; however, it must be recognized that what changes over time is not the production function itself, but rather the set of inputs that are available. This specification exploits the kind of additively separable functional form used by Dixit and Stiglitz (1977) to model differentiated consumption goods. It also follows Ethier (1982) in that the relevant differentiated commodities are inputs in production rather than consumption goods. Here, there is a single final consumption good.

To derive a reduced form expression for $Y$ as a function of $B, L, A$, and $I$, one must also specify how $x(\cdot)$ is related to $I$ and $A$. The different capital goods are produced in an intermediate goods sector that the reduced form specification of output $\gamma=F(B, L, I, A)$ hides. It uses designs for new types of capital goods from the research sector. If firm $i$ owns a design for capital good $i$, we assume that it can produce physical units of the capital good according to the same manufacturing technology as that used in the production of consumption goods. As a normalization of the unit of measurement of the durables, assume that one unit of forgone consumption generates one unit of any capital good. (Strictly speaking, one unit of consumption goods corresponds to one unit of capital for all different types of capital on a set of types of measure 1.) 
Let denote the total amount of capital goods in existence in the economy, $I=\int_{0}^{1} x(i) d i$. Because all of the different $x(i)$ goods are produced according to the same production technology, this sum across different types of goods makes sense. It represents the cost of the total quantity of durable capital goods in units of forgone consumption goods, and is close to the usual national income account measure of total physical capital.

It is now a simple matter to solve for the list $x(\cdot)$ and write down the reduced form expression for $Y$ as a function of $B_{Y}, L_{Y}, \boldsymbol{I}$ and 4 . Because the production technology for consumption goods and for each of the different capital goods is the same, total output in the manufacturing sector is the sum $Y=C+\dot{C}$. Given $\mathcal{A}$, it follows by symmetry that $x(i)$ will take on a common value $\bar{x}=I / \Lambda$ for all $i$ between 0 and $\Lambda$. Substituting the expression for $\bar{x}$ into equation (3) then yields

$$
Y=F\left(H_{\mathrm{Y}}, L_{\mathrm{Y}}, I, \Lambda\right)=(\not \Lambda \Lambda)^{\alpha}(L \Lambda)^{\beta} \boldsymbol{I}^{1-a-\beta}
$$

Even though the underlying production function for manufacturing goods described in equation (3) is homogeneous of degree 1 , this reduced from expression is homogeneous of degree $1+\alpha+\beta$ in $Z, L, A$, and $\boldsymbol{I}$. By Euler's theorem, it is impossible for this sector to be decentralized using perfect competition; paying each of the inputs $A, L, I, A$ its marginal product would more than exhaust total output. There are no spillovers and no external effects in the manufacturing sector. The increasing returns to scale are decentralized in this model through imperfect competition. The producer of good $i$ is the only supplier of this good. It therefore charges the monopoly price for it. Because of competition between different firms to produce good $i$, the present discounted value of the stream of monopoly profits will be equal to the price that is paid for the design for good $i$. This is how compensation is generated for the research sector. 
3.2 Functional forms and decentralization in the research sector

We assume that neither labor nor durables are used in research. Output of new designs is a function only of the stock of human capital employed and the stock of ideas that someone who does research has access to. This simple assumption is intended to reflect the fact that research is relatively intensive in human capital and ideas. Let $A$ and $I^{*}$ denote the stock of designs that have been produced in the home and foreign countries respectively. Let $4^{\text {world }}$ denote total stock of designs in the world as a whole. Because of redundancy, $d^{\text {world }} \leq \downarrow+\mathbb{1}^{*}$. To isolate the effects of restrictions on trade in goods, we will assume throughout this paper that integration in the sense of full communication of ideas is possible. Thus the entire stock of ideas contained in $4^{\text {world }}$ is available for researchers in each country. The effects of limitations of communication are described in a separate paper (Rivera-Batiz and Romer, 1990.) Then the output of designs for new goods in the home country can then be written as

$$
\dot{i}=\delta H_{\Lambda} \Lambda^{\text {world }} \text {. }
$$

In the foreign country it is

$$
\dot{i}^{*}=\delta B^{*} d^{\text {world }}
$$


This kind of specification is discussed in Romer (1990b). This model of research is easy to work with, but it has the disadvantage that it lets none of the specialized durable goods enter as an inputs in research. Machine tools probably are not important inputs in research, but other durables like computers are. Our companion paper (Rivera-Batiz and Romer, 1990) describes a parallel model that does let physical capital enter as inputs in research.

Decentralization of production decisions in the research sector involves spillovers of knowledge. The direct dependence of $i$ on $A^{\text {world }}$ reflects the role of external effects of spillovers of ideas from previous patents both at home and abroad. Holders of patents on the previous designs do not have any technological or legal means for preventing designers of new goods from using the ideas implicit in existing designs for purposes of discovering new designs. For this reason $A$ is not compensated in the research sector.

On the other hand, the holder of a patent on a design does have a legally enforceable property right on the use of the design for the purpose of manufacturing the associated good. Patents on designs confer monopoly power, and the associated monopoly rents provide the compensation for the researcher. Decentralization in manufacturing relies entirely on monopolistic competition while decentralization in research relies entirely on external effects.

\subsection{Preferences}

The technology so far describes the accumulation equations for $I$ and $A$. The stocks of $L$ and $I$ are taken as given. It would be useful to consider an extension that allowed $\mathrm{H}$ to increase over time as the average level of human capital in the population increases, but doing so here would add an additional state variable and require analysis off 
of a balanced growth path. This modification would contribute little to the analysis of trade policy and would greatly increase the complexity of the arguments.

It remains to specify the preferences that determine the split of resources between consumption $C$, investment in $\boldsymbol{Y}$, and investment in 1 . For comparability with other work, it is useful to evaluate this model in the context of the standard Ramsey preferences,

$$
\sigma=\int_{0}^{\infty} \frac{c^{1-\sigma}}{1-\sigma} \mathrm{e}^{-\rho t} d t
$$

The only way in which these preferences enter the computation of the balanced growth equilibrium is through the relationship that they imply between the rate of growth of consumption and the market interest rate:

$$
r=\rho+\sigma(\dot{C} / C)
$$

(For a derivation of this result, see the Appendix.) Any other rule that pins down the interest rate and the savings rate would suffice to close the model.

\section{Across the Board Protection}

This section describes the equilibrium in a world with two perfectly symmetric countries that impose the same tariff on all imported goods used in production. As noted above, throughout the paper, we assume that ideas can flow freely between different countries and focus only on flows of goods. In this section, we will also assume that international patent protection for designs is perfect so no copying of existing designs takes place. 
With these assumptions, we have ruled out any change in the degree of integration of the research sectors in the different countries and any change in redundancy in research. (The tariff will induce integration effects in the manufacturing sector that will reduce the level of income, but the focus here is not growth effects, not level effects.) For the example considered in this section, trade restrictions can therefore affect the rate of growth only by reallocating inputs between the growth and manufacturing sectors. In the next section we weaken the assumption that international patent protection is perfect and analyze a situation entailing redundant $R \& D$. As noted above, consideration of the integration effects in the research sector is sufficiently intricate to merit a separate treatment in the companion paper.

To describe a model with trade in goods explicitly, more notation is needed. Without trade, the quantity of an intermediate input $i$ that is used in a country is identical to the amount that is produced, and both usage and domestically produced stock can be denoted by the variable $x(i)$. With trade, production and usage in a country will differ. In what follows, $x(i)$ still denotes the stock of durable good $i$ that has been produced by firms in the home country; $x^{*}(i *)$ denotes the production of a different good in the foreign country. The goods indexed by $i$ and $i^{*}$ are completely different goods by assumption. Input 10 on the $i$ list could be a hard disk made in the United States; input 10 on the $i *$ list could be a computer display screen made in Japan. By our strong assumption on international patent protection, no firm creates a design for a good that already exists.

The notation used here reflects the fact that the index labels $i$ and $i *$ are merely names. The properties of a good are independent of which index is used to represent the good or the magnitude of the index. One can think of a master list of intermediate inputs from which all of the goods indexed by $i$ or $i^{*}$ are drawn. Particular intermediate inputs are placed on the $i$ and $i *$ lists as they are introduced, according to the country in which they are discovered. 
To describe the use of durable inputs by a final output firm in the home country, it is useful to have a separate notation for domestically produced and imported inputs. Let $d(i)$ denote domestic usage of durables produced in the home country, and let $m\left(i^{*}\right)$ denote home usage of durables produced in the foreign country. Then manufacturing output can then be written as

$$
\mathrm{Y}(B, L, d, m)=H_{Y}^{a} L^{\beta}\left[\int_{0}^{d} d(i)^{1-a-\beta} d i+\int_{0}^{d^{*}} m(i *)^{1-a-\beta} d i *\right]
$$

Symmetrically, foreign output is

$\mathrm{Y}^{*}\left(\mathbb{H}^{*}, \mathrm{~L}^{*}, d^{*}, m^{*}\right)=\mathbb{H}_{Y}^{*} a_{L}^{*} \beta\left[\int_{0}^{A} d^{*}\left(i^{*}\right)^{1-a-\beta} d i+\int_{0}^{A^{*}} m^{*}(i)^{1-a-\beta} d i\right]$

The home country imports $i^{*}$ goods while the foreign country imports $i$ goods. Some portion of these goods are used at home, the rest are exported. Figure 1 shows the usage of both domestically produced $i$ durables and imported $i *$ durables in the home country. Figure 2 illustrates the production of $i$ goods in the home country. Because of the symmetry between the different types of durables, domestic and foreign goods would be used at the same level if there were no tariffs. Both of the figures are drawn under the assumption that a positive tariff is charged by each government on imports of durables.

A domestic producer of an $i$-type good buys a design from someone who has developed it in the research sector. The firm that rents out durable good $i$ maximizes profit, choosing a level of output $d(i)$ to supply in the domestic market and a separate level $m^{*}(i)$ to supply in the foreign market. Because of the tariff charged on goods sold in the foreign market, the firm is free to segment these two markets and price discriminate, subject to the arbitrage constraint that the domestic price for the good must lie between 


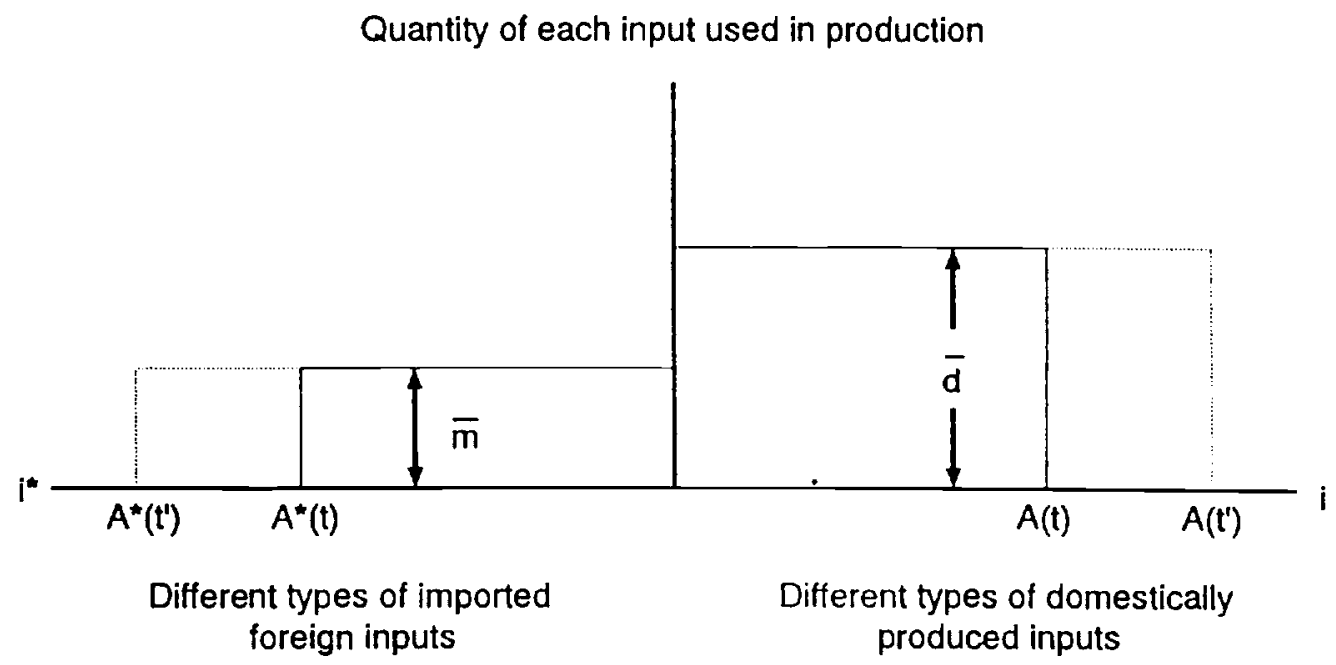

Figure 1: Inputs used in production at times $t$ and $t^{\prime}>t$.

the foreign price less the tariff and the foreign price inclusive of the tariff.

The domestic government imposes a tariff $\tau$ on the imports of $m$, so the price paid by domestic purchasers is $(1+\tau)$ times the price received by the foreign seller. The foreign government imposes a tariff $\tau^{*}$. In both countries, the tariff revenue is rebated to the consumers via a lump sum distribution. By the symmetry assumption, $\tau$ and $\tau^{*}$ are assumed to be the same, as are $L$ and $L^{*}$ and $H$ and $H^{*}$. The symmetric case has the advantage that the trade balance equation is always satisfied automatically.

Figures 1 and 2 also illustrate the evolution of the set of durables over time. Because of the symmetry among the goods, the durable good $i$ is supplied in the same quantity $\bar{d}$ in the home market for all $i$. Because of the tariff, a smaller quantity $\bar{m}^{*}$ is supplied in the foreign market. In the figure, 1 denotes the range of inputs produced at 


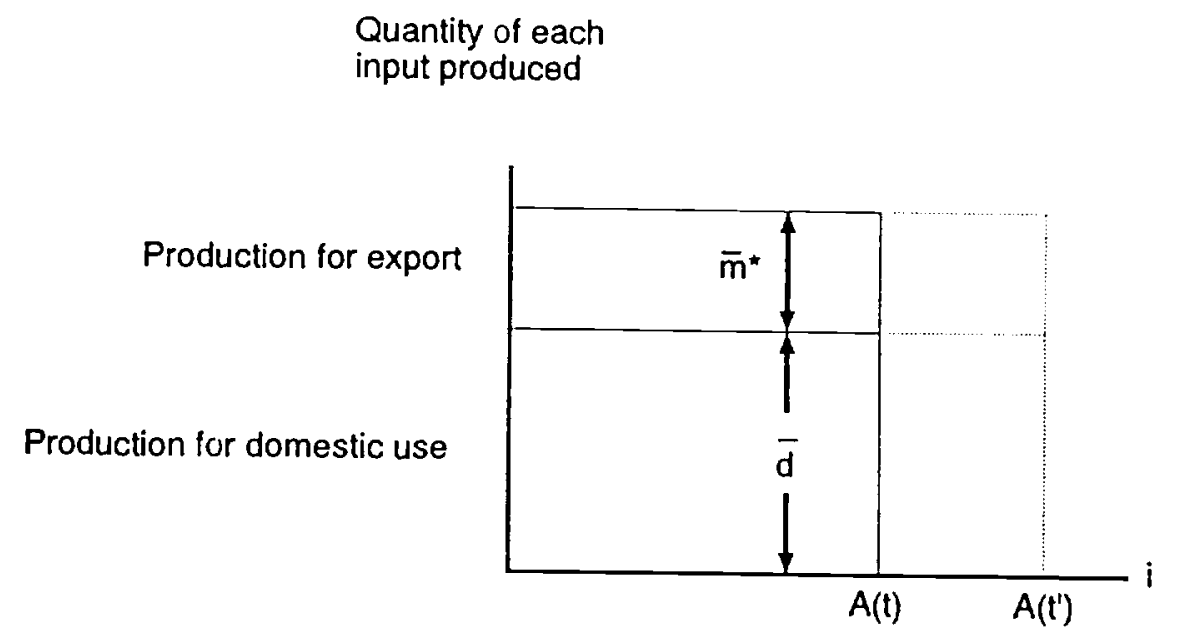

Different types of inputs produced domestically

Figure 2: Production of inputs at times $t$ and $t^{\prime}>t$.

home, $d^{*}$ the comparable range of inputs produced abroad. Over time, $A, A^{*}$, and $d^{\text {world }}=d+d^{*}$ all grow, but $\bar{d}$ and $\bar{m}^{*}$ remain constant. (For derivations of these results, see the Appendix.)

As noted above, tariffs change the degree of integration in the manufacturing sector, but they do not affect integration in the research sector. We have also assumed that international protection for patents is perfect, so no redundancy occurs. As a result, the only growth effects that changes in the tariff rate can have stem from allocation effects which shift human capital between manufacturing and research. As noted in the introduction, the surprising result in this model (explicitly derived in the appendix), is that the level of human capital used in research $\|_{A}\left(=Z_{A}^{*}\right)$ is not a monotonic function of the tariff rate, and hence neither is the rate of growth. The expression for the common rate of 
growth in the two countries is

$$
g(\tau)=\frac{2 \delta B-\Lambda \rho f(\tau)}{\Lambda \sigma f(\tau)+1}
$$

where the function $f(\tau)$ is defined by

$$
f(\tau)=\frac{1+(1+\tau)^{-(1-a-\beta) /(a+\beta)}}{1+(1+\tau)^{-1 /(a+\beta)}}
$$

Figure 3 plots an illustrative graph of the growth rate $g(\tau)$. (The specific parameter values used to generate this graph are described in the Appendix.) For any $\tau>0$, the growth rate is strictly less than the rate of growth $g(0)$ with no tariffs. The growth rate $g(\tau)$ first falls with $\tau$, reaches a minimum, and then begins to increase. In the limit as $\tau$ goes to $\infty, g(\tau)$ approaches the free trade growth rate $g(0)$. As the figure shows, however, the return back to the zero tariff growth rate is very slow.

This nonmonotonicity of the growth rate in the tariff rate arises because two offsetting forces influence the allocation of human capital. Symmetric increases in the tariff rate $\tau\left(=\tau^{*}\right)$ have effects on the return to human capital in both research and in manufacturing. An increase in $\tau^{*}$ represents a tax by the foreign government on the monopoly rents that the purchaser of a new design can extract from exports of the good. A higher tariff reduces imports by the foreign country $m^{*}$ and therefore depresses the price of new designs. Everything else equal, this would cause human capital to shift out of research.

Everything else, however, is not equal. An increase in $\tau$ (which under our symmetry assumption also implies an increase in $\tau^{*}$ ) also reduces the quantity of imported intermediate inputs $m$ used by domestic manufacturers of final output. This reduces the 


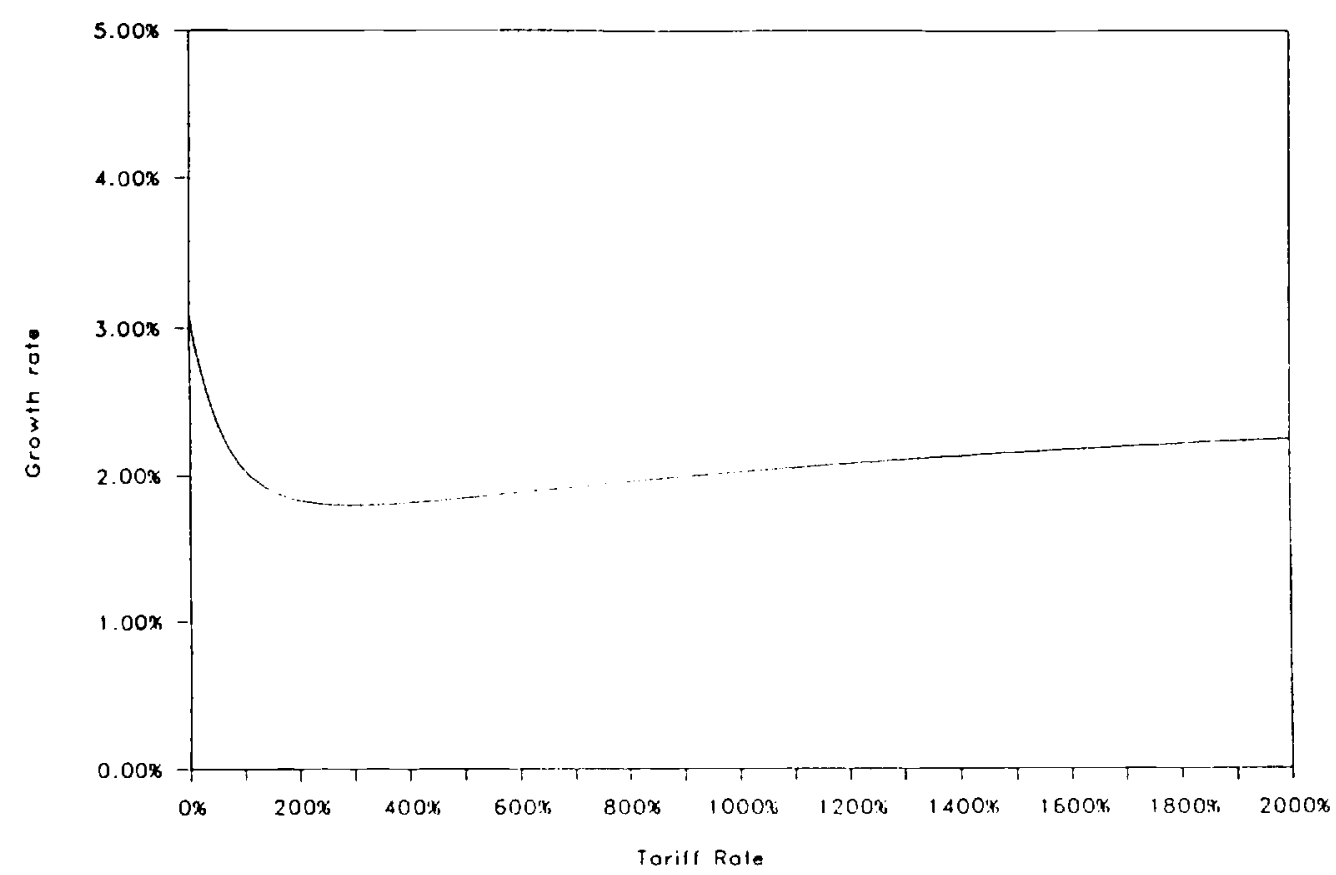

Figure 3: The worldwide growth rate as a function of the common tariff rate

marginal productivity of human capital in manufacturing. The net effect on the allocation of human capital depends on which of these effects is larger. Equation A.12 in the appendix shows that the marginal product of human capital in manufacturing depends on a term proportional to $m(\tau)^{1-a-\beta}$, whereas the revenue extracted by the holder of a patent on a new design depends on a term proportional to $(1+\tau)^{-1} m^{*}(\tau)^{1-\alpha-\beta}$. By symmetry, $m(\tau)=m^{*}(\tau)$. Initially, the effect on patent revenue, $-(1+\tau)^{-2} m^{*}(\tau)^{1-a-\beta}$ $+(1+\tau)^{-1}(1-a-\beta) m^{-a-\beta} \frac{\partial m}{\partial \tau}$ has a larger absolute value than the effect in manufacturing, $(1-a-\beta) m^{-a-\beta} \frac{\partial m}{\partial \tau}$. As $\tau$ goes to $\infty$ and $(1+\tau)^{-1}$ goes to 0 , the relative magnitudes reverse.

When there are two effects that conflict, there will typically exist modifications of the model that will cause the effect that dominates to change. The correct general 
conclusion that can be drawn is that to the extent that trade restrictions have only allocation effects, the restrictions can have an ambiguous effect on the rate of growth. This is especially true in cases where there is an important asymmetry between two trading partners because the allocation effects of trade are likely to be larger in this case.

The example presented here shows that starting from realistic levels of tariff, if two similar countries increase their tariffs on imports produced in a monopolistically competitive sector, the net effect will be to drive resources out of that sector. This will reduce the rate at which goods in these sectors are introduced because the dominant effect of an increase in the tariffs is to reduce the rents that provide compensation for research. If the assumption made here is correct - that goods with high fixed research and development costs play an important role in generating growth - then starting from realistic levels of tariffs, symmetric worldwide increases in tariffs on the goods that result from research and development will reduce the worldwide rate of growth.

\section{Selective Protection with imperfect intellectual property rights}

In the last section, the assumption that ideas flowed freely bet ween nations meant that trade policy had no effect on integration in the research sector. The assumption that patent protection for ideas was perfect meant that regardless of the trade regime, no redundancy occurred. As a result, trade policy could affect the rate of growth only because of the induced allocation effects. In this section, we weaken the assumption that patent protection is perfect and show that trade in goods can reduce redundancy as well. 


\subsection{Patent Protection, Copying, and Trade Barriers}

If there is no trade in goods, there is no competitive reason to design a good that is different from one that exists in a foreign market. If we assume that it is cheaper to copy a foreign good than it is to design a new one, there is an incentive to copy if the costs of circumventing the legal protection are not too high. If, on the other hand, there is trade in goods, a firm faces an offsetting incentive to produce an entirely new design; a new good generates monopoly rents, whereas an existing good will lead to a duopoly game with another producer. Holding constant the degree of legal protection, trade in goods alone can therefore reduce redundant research effort by reducing the payoffs to someone who copies.

We formalize the idea that it is possible to circumvent patent protection and copy an existing design in the following way. Given a stock of general knowledge $\boldsymbol{A}^{\text {world }}$ and a quantity $B$ of human capital, it is possible to produce $\delta \not A$ new designs per unit time or OHA copies of existing designs, with $\theta>\delta$. Part of the design cost required for copying a good might be needed to uncover aspects of the good that are not immediately apparent. An additional part of the design work is needed to make design changes that have no effect on how the good functions, but are intended merely to avoid patent infringement charges under the legal system. The assumption that $\theta$ is bigger than $\delta$ then implies that the amount of research needed to understand an existing good and to circumvent the patent is smaller then the research needed to design a new good.

To make our point as simply as possible, we want to make assumptions which guarantee that a firm that can copy a good and compete with an existing producer will not choose to do so, but that a firm that can copy a foreign good and sell in a market that is protected from the foreign producer's competition will choose to do so. For simplicity, protection from the foreign producer is assumed to take the form of selective quantity limits imposed by the government on imports. Imports for a fixed fraction $q$ of the 
durable goods produced abroad will be set to zero. Equivalently, a prohibitive tariff is applied to these goods.

A researcher in the domestic country then has three options: (1) designing a new good and earning monopoly rents in the world market; (2) copying a good from abroad that is not allowed to enter the domestic market and earning monopoly rents from the domestic market alone; and (3) copying a good that is already being sold in the domestic market and playing a duopoly game In the second case, the copying firm is assumed to be unable to sell in the foreign market because the foreign firm whose good has been denied entry into the home market can induce its government to restrict imports of the copies.

In the symmetric case considered here, the world market is twice the size of either domestic market. For the constant elasticity demand curves used here, prices are independent of market size so that profits are proportional to the size of the market. It is therefore more profitable to copy an excluded foreign good and sell it in the protected domestic market than it is to develop an entirely new good whenever copying is more than twice as easy as innovating, i.e. whenever $\theta$ is greater than $2 \delta$. We assume that this is true.

We also need an upper bound on how easy it is to copy. If copying were arbitrarily inexpensive (i.e. if $\theta$ were arbitrarily large) it would be worthwhile to copy a good that has not been excluded and play a duopoly game even if that game yields a very small profit. We impose a second restriction on $\theta$ that avoids this possibility. Specifically, we assume that $\theta$ is not too large and that the expected payoff from the duopoly game that would ensue after copying is not large. For example, if firms expect Bertrand competition in the duopoly game, copying will never take place in the absence of protection, no matter how big $\theta$ is relative to $\delta$. If firms expect Cournot competition, copying will not take place unless $\theta$ exceeds $2 \delta$ by a large enough margin to make duopoly a feasible equilibrium. For instance, in the case in which $\alpha+\beta$ equals .7 , copying is not profitable if $\theta$ is less than $3 \delta$. 
Given these assumptions on 0 and $\delta$ and implicitly on the duopoly game, the most profitable strategy is to copy an excluded foreign good and sell it in a protected market if this is possible. The next most profitable strategy is to design a new good and sell it worldwide. The third strategy, to copy a good that is not excluded and play a duopoly game, is dominated by the second strategy.

The notation must now reflect the existence of three types of goods. Goods indexed by $i$ continue to represent durable inputs designed and produced at home that are sold in both the domestic and foreign markets. Symmetrically, goods indexed by $i *$ represent inputs designed and produced abroad that are sold in both markets. A new index $j$ ranging from 0 to $J$ represents nontraded goods. The range of nontraded goods indicates the total number of goods that have been designed in one country and copied in the other. The total measure of copied goods $J$ is proportional to the total amount of effort by human capital that has been devoted to the socially worthless activity of producing redundant designs.

From the point of view of the home country, a good can become a $j$ good in one of two ways. Either it is a newly designed good that is refused entry into the foreign market by the foreign government, or it is a copy of a foreign good that is refused entry into the home market by the domestic government. Since copying goods for sale in a protected market generates pure profits, all goods that are denied entry into a country are copied. As a result, the set of $j$ goods is the same in the two countries.

The arbitrary timing assumed here is as follows. Over a small interval of time, some new goods are introduced in the foreign market and are prohibited from entry into the domestic market. The right to earn a pure profit by copying one of these goods and selling it in the protected home market is allocated to a domestic firm. To allocate this opportunity to copy, domestic firms could be required to bid for a license from the government to produce such a good. To highlight the effects of trade alone, we assume that no resources are wasted in deciding which domestic firm gets the right to produce 
copies in the domestic market. That is, we assume away rent seeking activities in the usual sense. All of the unproductive effort expended here arises purely from effort exerted to reverse engineer a good that has already been designed.

Some researchers at home are engaged in reverse engineering of the foreign, excluded durable goods. Others produce new designs and sell them to firms that will manufacture the new inputs. A firm begins manufacturing, attempts to export the good, and then is told by the foreign government whether its good will be refused entry (which happens with probability q) or allowed to enter (with probability $1-q$ ). In keeping with the symmetry assumption, the foreign and home governments exclude the same fraction $q$ of goods from the other country. Because this represents a diversifiable risk, the price the manufacturer pays for a design is the expected monopoly profit that it will generate. This is equal to $q$ times the monopoly profit that can be extracted from sales in the domestic market alone plus $1-q$ times the monopoly profit that can be extracted from sales in the the home market and the foreign market taken together.

The incentive for a government to prohibit imports of foreign goods comes from the fact that this offers a way to capture ex post monopoly rents that would otherwise flow to foreign nationals. A more direct way to expropriate these rents from forcigners is to intentionally weaken patent protection, especially if this can be done in a selective way that preserves intellectual property rights for domestic citizens but undermines them for foreigners. Here we focus only on trade in goods and defer consideration of policy decisions about patent rights and the legal system for future work. In the example we consider here, we focus only on the ways in which restrictions on flows of goods can be used to aid in this process of expropriation. We assume that patent protection applies equally to all designs regardless of the ownership, and that the extent of patent protection is not varied when the barriers to goods flows are varied (i.e. when the fraction of excluded goods $q$ is varied.) 


\subsection{Redundancy and Growth}

Output of final goods in the home country can be written as

$$
\begin{aligned}
\mathrm{Y}(B, L, \mathrm{~d}(\cdot), m(\cdot), n(\cdot))=\mathbb{H}_{\mathrm{Y}}^{a} L^{\beta}[ & \int_{0}^{I} d(i)^{1-\alpha-\beta} d i+ \\
& \left.\int_{0}^{I^{*}} m\left(i^{*}\right)^{1-a-\beta} d i *+\int_{0}^{J} n(j)^{1-\alpha-\beta} d j\right] .
\end{aligned}
$$

A producer of final goods in the horne country can make use of the three types of goods. For $0 \leq i \leq I, d(i)$ represents use of domestically designed and produced goods that are sold in both markets. For $0 \leq j \leq J, n(j)$ represents the use of nontraded goods that are produced at home. The total stock of designs produced in the home country $A$ is equal to the sum $\Delta=I+J$. As before, $m(i *)$ represents imports of goods designed and produced abroad, $i *$ indexes these goods. Now, however, $i *$ ranges from 0 to $I^{*}$ instead of from 0 to $1^{*}$. The total stock of goods designed and produced in the foreign country is $1^{*}=$ $I^{*}+J$, but only the $I^{*}$ goods trade.

The expression for the output of final goods in the foreign country is symmetric with that of the domestic country. A firm in the foreign country will use $d^{*}\left(i^{*}\right)$ of locally produced traded goods for $0 \leq i * \leq I^{*}$. It will also use $m^{*}(i)$ of goods designed and produced in the home country for $0 \leq i \leq I$, and $n^{*}(j)$ units of nontraded goods for $0 \leq j \leq J$. Note the difference in the notation that is induced by the redundancy. Both lists $n(\cdot)$ and $n^{*}(\cdot)$ depend on the same index $j$. Good 34 on the $j$ list is the same good in each country, regardless of the country in which it was first designed and produced. Since $I$ and $I^{*}$ measure the disjoint sets of traded inputs produced in each country, and $J$ measures the set of nontraded inputs available in each, the measure of the worldwide stock of distinct inputs and distinct design knowledge is $A^{\text {world }}=I+I^{*}+J<A+A^{*}$. 
To complete the specification of this model, it remains to describe how $A^{\text {world }}$, $I$, $I^{*}$, and $J$ evolve. Now there are three different activities in which human capital can be used: manufacturing, denoted by $Z_{Y}$; research on new goods, denoted now by ${ }_{N}$ ("N" for new); and copying of existing designs, denoted by ${ }^{H}$ ( $" C$ " for copy). When human capital $Z_{N}$ is used in research at home, the implied rate of growth of designs $I$ that trade internationally is

$$
\dot{I}=(1-q) \delta H_{N} d^{\text {world }}
$$

A quantity of human capital equal to $Z_{N}$ produces $\delta H_{N} d^{\text {world }}$ new designs per unit time, but only a fraction $1-q$ of these are allowed to trade internationally. Symmetrically, the growth of $I^{*}$ is given by

$$
\dot{I}^{*}=\left(1-q^{*}\right) \delta \ddot{B}_{N}^{*} d^{\text {world }}
$$

The quantity of nontraded intermediate inputs grows as new inputs produced at home are excluded from the foreign market and as copying of foreign goods takes place at home:

$$
\dot{J}=q^{*} \delta H^{d^{d}}{ }^{\text {world }}+O H C^{d^{\text {world }}}
$$

The range $J$ grows by the same amount, for the same reasons, in the foreign country:

$$
j=\mathrm{q} \delta H_{N}^{*} d^{\text {world }}+O H^{*} C^{A^{\text {world }}}
$$

Because copying generates pure profits, it is constrained only by the supply of goods produced abroad that are excluded from the home market. Consequently, ${ }_{C}{ }$ is 
determined by ${ }^{O B} c^{\Lambda^{\text {world }}}=\mathrm{q} \delta B^{*} d^{\text {world }}$. It follows by substitution and symmetry that

$$
j=\mathrm{q} \delta \|_{N}^{*} d^{\text {world }}+\mathrm{q}^{*} \delta H_{N^{1}}{ }^{\text {world }}
$$

By adding equations (8), (9), and (11), it follows that $\dot{i}^{\text {world }}=\dot{I}+\dot{I}^{*}+\dot{J}$ is given by

$$
i^{\text {world }}=\delta\left(H_{N}+H_{N}^{*}\right) d^{\text {world }} .
$$

All human capital devoted to research on new goods contributes to the growth of $4^{\text {world }}$. The difference now is that a portion ${ }^{B^{+}} \mathbb{H}_{C}^{*}$ of the total worldwide stock of human capital is devoted to the socially unproductive activity of copying existing designs.

Given the discussion so far, it should come as no surprise that increases in the restrictions on trade in this model unambiguously reduce growth. First, the human capital ${ }^{B} C^{+H_{C}^{*}}$ that is induced into copying acts like a reduction in total worldwide human capital. Since the growth rate is increasing in the total stock of human capital, this reduces the rate of growth. This is the redundancy effect of trade protection. In the absence of the trade restrictions that create the incentive for copying, this amount of human capital would be put to a socially productive use.

In addition, growth is lower still because copying acts like a tax on the revenue generated by a new design. With probability $q$, all of the profit that would otherwise be collected from the foreign market is taken away. This reduction in the marginal productivity of human capital in research is not offset by any reduction in the marginal productivity of human capital in manufacturing. The manufacturing industries in both countries always use all of the inputs that exist in the world. Thus in this case, the allocation effect of the copying acts unambiguously to reduce growth. 
The formal expression for the growth rate as a function of $q=q^{*}$ derived in the appendix is

$$
g=\frac{2 \delta H-\frac{2 \Lambda \rho}{2-q}}{\frac{2 \Lambda \sigma}{2-q}+q \frac{\delta}{\partial}+1} .
$$

This expression for $g$ is monotonically decreasing in $q$.

\section{Conclusions}

The first of our two examples shows that if North Americans were to use a tariff to apply broad restrictions on all newly invented goods imported from Europe, and Europeans put the same tariff on all newly invented goods from the United States, then invention would be a less rewarding activity in both places and technological progress would slow down. Formally, the result allows for the possibility that at very high levels of protection, the effect of higher trade restrictions might be to reduce other opportunities so much that more people become inventors despite the fact that returns to invention fall. The theoretical results, like common sense, suggest that while logically possible, this possibility is not important in practice.

The second example suggests that if Europeans and North Americans use targeted protection for specific goods to extract ex post monopoly rents that would otherwise flow to foreigners, research effort on new goods will be less rewarding, and valuable resources will be diverted from manufacturing and research into socially useless redundant activities. For both reasons, growth rates will fall.

Unambiguous results emerge in these two examples because of the specific details of the experiments that we consider. Of particular importance, we impose symmetry 
throughout our analysis, in both the endowments and technologies faced by each country, and in the policies that are implemented. This lets us highlight the sense in which trade exploits international increasing returns, and lets us minimize the obscuring effects that arise when trade induces large flows of resources between different sectors.

Our focus should not be taken to imply that differences in endowments, technologies, or policies are always unimportant. For example, in their analysis of product cycle model of trade between a developed North and a less developed South, Grossman and Helpman $(1989 \mathrm{~b}, \mathrm{~d})$ have shown that policy changes the make it easier for a less developed Southern country to imitate goods invented in the North may speed up the worldwide rate of growth. In this case, the redundancy effects of copying (which are bad for growth) are overwhelmed by the allocation effect of shifting manufacturing from the North to the South, and thereby freeing resources in the North for additional research. Additional copying in this setting can increase the worldwide rate of growth.

In some settings, policy chosen by different countries will also be different. As first noted by Frank Graham (1923) in his analysis of trade policy with Marshallian increasing returns, the kind of policy favored by a developing country may be very different from that favored by an advanced country. Followers may prefer some kind of infant industry protection while leaders prefer free trade. For a recent analysis of this kind of issue in an endogenous growth model, see Lucas (1988) and Young (1990).

Our results are therefore specific to a particular context - trade between similar developed countries. Other questions posed in other contexts may well lead to different answers. There results show, nonetheless, that the emerging theory of trade and growth can generate unambiguous conclusions in cases of practical interest.

With the formalization of the new theory of trade (as carried out by Krugman 1979, 1981, Lancaster 1980, Helpman 1981, and Ethier 1982), it is now clear that the gains from trade can arise from at least $t$ wo fundamental sources: differences in comparative advantage and economy-wide increasing returns. One of the difficulties that these two 
effects present for theorists is that they sometimes offset each other. Consequently, it is no longer possible to make completely general, unqualified statements about what the effects of trade restrictions will be. When the model under consideration is augmented from a static model or a dynamic model with steady states into a model with endogenous growth, the multiplicity of possible outcomes can at first be all the more daunting.

But even though we know that demand curves sometimes slope down and sometimes slope up, economists still have something useful to say about demand theory. We know that in some problems (e.g. the response of savings to changes in the interest rate) income effects can be very important and upward sloping demand curves are a real possibility. We also know that in many other cases, income effects will reinforce substitution effects, or will be small and can be ignored. In either of these cases, demand curves will slope down. By combining a theoretical decomposition of price changes into income and substitution effects with accumulated evidence about income elasticities, we have learned that there are many cases where the effects of price changes can be predicted with confidence. We hope that the decomposition proposed here can serve a similar purpose. Once economists have developed similar evidence about the magnitude and direction of the allocation effects of trade restrictions, we should be able to predict the effects that trade restrictions have on growth with the same confidence as when we predict the effect of a price change on demand. 


\section{REFERENCES}

Dixit, Avinash and Joseph Stiglitz, "Monopolistic Competition and Optimum Product Diversity." American Economic Review 67 (June 1977), 297-308.

Dinopoulos, Elias, James Oehmke, and Paul Segerstrom, "High Technology Industry Trade and Investment: The Role of Factor Endowments," University of Florida working paper (1990).

Ethier, Wilfred J., "National and International Returns to Scale in the Modern Theory of International Trade." American Economic Review 72, (June 1982): 389-405.

Feenstra, Robert, "Trade and Uneven Growth," National Bureau of Economic Research, Working Paper No. 3276 (1990).

Graham, Frank D., "Some Aspects of Proptection Further Considered." Quarterly Journal of Economics 37, (February 1923): 199-227. ,

Grossman, Gene and Elhanan Helpman, "Growth and Welfare in a Small Open Economy," National Bureau of Economic Research, Working Paper No. 2809 (1989a) and , "Endogenous Product Cycles" NBER Working paper No. $2913,1989 \mathrm{~b}$. and , "Quality Ladders in the Theory of Growth," National Bureau of Economic Research, Working Paper No. 3099, (1989c). 
and , "Quality Ladders and Product Cycles,"

National Bureau of Economic Research, Working Paper No. 3201 (1989d). and , "Comparative Advantage and Long Run

Growth" American Economic Review 80 (September 1990), 796-815.

Helpman, Elhanan, "International Trade in the Presence of Product Differentiation, Economies of Scale, and Monopolistic Competition: A Chamberlinian-HeckscherOlin Approach," Journal of International Economics 11 (1981), 305-340.

Krugman, Paul, "Increasing Returns, Monopolistic Competition, and International Trade," Journal of International Economics 9 (November 1979), 469-479.

, "Intraindustry Specialization and the Gains from Trade," Journal of Political Economy 89 (October 1981), 959-73.

Lancaster, Kevin, "Intraindustry Trade under Perfect Monopolistic Competition," Journal of International Economics 10 (1980), 151-75.

Lucas, Robert E. Jr., "On the Mechanics of Economic Development." Journal of Monetary Economics 22 (1988), 3-42.

Rivera-Batiz, Luis A. and Paul M. Romer, "Economic Integration and Endogenous Growth." Quarterly Journal of Economics (May 1991), forthcoming. 
Romer, Paul, "Are Nonconvexities Important for Understanding Growth?" American Economic Review 80 (May 1990a), 97-103. "Endogenous Technological Change." Journal of Political Economy, 98 (October 1990b), S71-S102.

Segerstrom, Paul, T. C. A. Anat and Elias Dinopoulos, "A Schumpeterian Model of the Product Life Cycle." American Economic Review, forthcoming (1990).

Young, Alwyn, "Learning by Doing and the Dynamic Effects of International Trade." Quarterly Journal of Economics, forthcoming (May 1991). 
Appendix

A.1 Results from section 4 in the text

The production function for the final output sector in the home country is given in equation (6a). This constant returns to scale production function leads to the usual indeterminacy in the number or price-taking firms and the scale of production for each firm. Since aggregate output is determined, we can focus on the sector's total output and derive the aggregate demand for each good $x(i)$ by solving a maximization problem that is conditional on given levels of $B_{Y}$ and $L$ for the industry as a whole. Leaving aside the exogenous wage bill, the maximization problem can be represented as :

$$
\max _{d, m} Y\left(H_{Y}, L, d(.), m(.)\right)-\int_{\mathbb{R}_{+}} P_{d}(i) d(i) d i-\int_{\mathbb{R}_{+}}(1+\tau) P_{m}^{*}(i *) m(i *) d i *
$$

where $P_{d}$ refers to the home price of domestic inputs and $P_{m}^{*}$ is the price received by foreign producers for their exports. (Both of these prices, and all other prices quoted for durables are rental prices.) We will henceforth treat the range of integration as being $\mathbb{R}_{+}$ and implicitly treat any good with $i>\downarrow$ or $i^{*}>\downarrow^{*}$ (that is any good that has not been invented yet) as having an infinite price. The price $P_{m}^{*}(1+\tau)$ is paid by domestic users of foreign inputs; it is greater than the price received by foreign producers due to the tariff $\tau$ applied in the home country. The price of the single final output good, which is freely traded, must be the same in the two countries. It is taken as the numeraire.

The first order necessary conditions for the choice of $d(i)$ and $m\left(i^{*}\right)$ in the 
domestic manufacturing sector are:

$$
\begin{gathered}
(1-a-\beta) B_{\mathrm{Y}}^{a} L^{\beta} d(i)^{-a-\beta}-P_{d}(i)=0 \\
(1-a-\beta) B_{Y}^{a} L_{m\left(\mathrm{i}^{*}\right)}^{\beta^{-a-\beta}}-(1+\tau) P_{m}^{*}(i *)=0
\end{gathered}
$$

The implied derived demands for domestic and imported inputs are:

$$
\begin{gathered}
d(i)=(1-a-\beta)^{1 /(a+\beta)}{ }_{H_{Y}}^{a /(a+\beta)} L^{\beta /(a+\beta)} P_{d}(i)^{-1 /(a+\beta)} \\
m\left(i^{*}\right)=(1-a-\beta)^{1 /(a+\beta)}{ }_{H_{Y}}^{a /(a+\beta)}{ }_{L}^{\beta /(a+\beta)}(1+\tau)^{-1 /(a+\beta)} P_{m}^{*}(i *)^{-1 /(a+\beta)}
\end{gathered}
$$

An analogous procedure yields the first order necessary conditions for the foreign country's choice of $d^{*}\left(i^{*}\right)$ and $m^{*}(i)$ in the symmetric tariff case $\left(\tau=\tau^{*}\right)$ :

$$
\begin{gathered}
(1-a-\beta) z_{Y}^{*} a_{L}^{*} \beta_{d^{*}(i)^{-a-\beta}-P_{d^{*}}^{*}(i *)=0} \\
(1-a-\beta) B_{Y}^{*} a_{L}^{*} \beta_{m^{*}(i)^{-\alpha+\beta}-(1+\tau) P_{m^{*}}(i)=0}
\end{gathered}
$$

The implied derived demands for locally produced and imported inputs abroad are:

$$
\begin{aligned}
& d^{*}\left(i^{*}\right)=(1-a-\beta)^{1 /(\alpha+\beta)} B_{Y}^{*} a /(a+\beta) L^{*} \beta /(a+\beta) P_{d^{*}}^{*}(i *)^{-1 /(a+\beta)}
\end{aligned}
$$

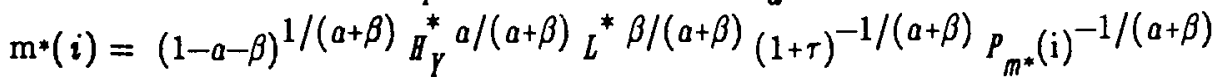

$P_{d^{*}}^{*}$ is the price (set by foreign firms on foreign goods) of foreign inputs. $P_{m^{*}}$ (set by home firms on goods imported by foreigners) is the price received by home producers. $\left(1+\tau^{*}\right) P_{m^{*}}$ is the price paid by the foreign users of these goods. 
In equilibrium, the production $x(i)$ of a representative domestic input is equal to the sum of domestic usage $d(i)$ and exports $m^{*}(i)$. Since all domestic producers face the same demand and have identical cost functions, we can ignore the index $i$ and write the demand as a function of the appropriate price, $d\left(P_{d}\right)$ and $m^{*}\left(P_{m^{*}}\right)$. Total production $x$ of an intermediate input in the home country can then be expressed as $x\left(P_{d^{\prime}}, P_{m^{*}}\right)=d\left(P_{d}\right)+m^{*}\left(P_{m^{*}}\right)$.

The presence of a tariff barrier generates a range $P_{m^{*}}<P_{d}<(1+\tau) P_{m^{*}}$ within which domestic producers can engage in price discrimination between foreign and domestic markets. Outside of this range, purchasers in one country could earn arbitrage profits by reselling in the other country. Domestic firms will set output levels in each market and charge prices to maximize total profits. Recalling that the prices are rental prices, revenue as a function of the quantities $d$ and $m^{*}$ is $P_{d^{\prime}}(d) d+P_{m^{*}}\left(m^{*}\right) m^{*}$. Because it costs one unit of forgone output to produce one unit of capital, the flow opportunity cost of these units is $r\left(d+m^{*}\right)$. The instantaneous rate of profit earned by the holder of the patent is therefore

$$
\pi=\max _{d, m^{*}} P_{d}(d) d+P_{m^{*}}\left(m^{*}\right) m^{*}-r\left(d+m^{*}\right)
$$

Equating each market's marginal revenue to marginal costs and substituting for $P_{d}(d)$ and $P_{m^{*}}\left(m^{*}\right)$ from (A.2) and (A.7), yields a pair of pricing equations for domestic and foreign sales: $P_{d}=r / 1-a-\beta$ and $P_{m^{*}}=r / 1-a-\beta$. These pricing functions represent identical markups over marginal cost, $r$. Thus we can drop the distinction between domestic prices $P_{d}$ and prices received in foreign markets $P_{m^{*}}$ and represent both of them by the symbol p. Similar considerations applied to foreign firms show that their optimal pricing functions are $P_{d^{*}}^{*}=P_{m}^{*}=r^{*} / 1-a-\beta$. Furthermore, free flows of the final consumption good and free borrowing and lending imply that and interest rates must be equalized across countries $\left(r=r^{*}\right)$. As a result, durables bear the same price $p=p^{*}$ 
in both countries. We can therefore conclude that

$$
p=p^{*}=\frac{r}{1-a-\beta}
$$

This fixed price is associated with constant values for $d=d^{*}$ and $m^{*}=m$ that are denoted by with overbars: $\bar{d}, \bar{m}$.

Free entry into the durables sector ensures that the discounted value of revenue minus variable costs equals design $\cos t P_{A}$

$$
P_{\mathcal{A}}(t)=\int_{\mathbb{R}_{+}} e^{-\int_{t}^{s^{\prime}} \mathrm{r}(s) d s} \pi\left(s^{\prime}\right) d s^{\prime}
$$

Differentiating with respect to time yields an arbitrage equation relating the interest rate to current profits per dollar invested plus the percentage change in the value of designs over time,

$$
r=\frac{\pi(t)}{P_{1}}+\frac{\dot{p}_{1}}{P_{i}}
$$

We seek a solution characterized by a constant value for $P_{A}$, in which case the arbitrage equation reduces to:

$$
P_{A}=\frac{\pi(\mathrm{t})}{r}=\frac{1}{r}\left[p\left(\bar{d}+\bar{m}^{*}\right)-r\left(\bar{d}+\bar{m}^{*}\right)\right]=\left(\frac{p}{r}-1\right)\left(\bar{d}+\bar{m}^{*}\right)
$$

Substituting $p / r=1-a-\beta$ from (A.10), and using $p=(1-a-\beta) t_{Y}^{\alpha} \mathrm{L}^{\beta}(\bar{d})^{-a-\beta}$ $=(1+\tau)^{-1}(1-a-\beta) B_{Y^{L}}^{\alpha} \beta_{\bar{m}^{*}}-a-\beta$ from (A.2) and (A.7), we obtain a relation between $P_{A^{\prime}}, r$, $\bar{d}$, and $\bar{m}^{*}$, 


$$
P_{L}=(a+\beta) \frac{p}{r}\left(\bar{d}+\bar{m}^{*}\right)=\frac{a+\beta}{r}(1-\alpha-\beta) H_{Y}^{a} L^{\beta}\left[\bar{d}^{1-\alpha-\beta}+(1+\tau)^{-1} \bar{m}^{*} 1-a-\beta\right] .
$$

Equating the marginal product of labor in research, $\delta P_{A} d^{\text {world }}$, to that in manufacturing, $\frac{\partial Y}{\partial H_{Y}}$, yields

$$
\begin{aligned}
& \delta \frac{\alpha+\beta}{r}(1-a-\beta) R^{a} L^{\beta} \Lambda^{\text {world }}\left[\bar{d}^{1-a-\beta}+(1+\tau)^{-1} \bar{m}^{*} 1-a-\beta\right] \\
& =a \mathbb{H}_{Y}^{a-1} L^{\beta}\left[\Lambda \bar{d}^{1-\alpha-\beta}+\perp^{*} \bar{m}^{1-a-\beta}\right] .
\end{aligned}
$$

To solve for $A_{Y}$, we impose the symmetry condition $A / A^{\text {world }}=A^{*} / A^{\text {world }}=1 / 2$, and make use of the relation $\bar{m}=\bar{m}^{*}=\bar{d}(1+\tau)^{-1 /(\alpha+\beta)}$, which follows from (A.4), (A.5), and (A.9) since $p_{d}=p_{m}^{*}=p_{m^{*}}$. This yields a formula for $B_{Y}$ in terms of $r$ :

$$
H_{Y}=\frac{1}{2 \delta} f(\tau) \mathbf{r}
$$

where $\Lambda=\frac{a}{(\alpha+\beta)(1-\alpha-\beta)}$ and $f(\tau)=\frac{1+(1+\tau)^{-(1-a-\beta) /(\alpha+\beta)}}{1+(1+\tau)^{-1 /(\alpha+\beta)}}$. Equation (A.13) provides the basic technological relation between $g$ and $r$ for the model. In order to solve for $r$ and $B_{d}=B-B_{\gamma}$, we must consider the preference side of the model, which will determine the other relation involving $r$.

Let $T(t)$ denote the redistribution of tariff revenues through rebates, let $w$ denote the wage for labor, and let $w_{B}$ denote the wage for human capital. Also, let $D(t)$ denote the consumer's holdings of debt instruments, and assume that all firms are $100 \%$ debt-financed. (With no uncertainty, debt is equivalent to equity.) The utility 
maximization problem can be written as

$$
\begin{gathered}
\max _{C(.)} U(C(\cdot))=\int_{0}^{\infty} e^{-\rho t} \frac{C(t)^{1-\sigma}}{1-\sigma} \mathrm{d} t \\
\text { subject to } D=r D+\omega(t) L+w_{H}(t) H+T(t)-C(t) .
\end{gathered}
$$

For now we treat $r$ as a constant in the consumers problem. We show below that this is consistent with the equilibrium conditions on the production side as well. The Hamiltonian for this problem is

$$
\mathscr{H}=\max \frac{C(t)^{1-\sigma}}{1-\sigma} e^{-\rho t}+\lambda\left[r D+w(t) L+w_{H}(t) H+T(t)-C(t)\right]
$$

with associated Hamiltonian equations

$$
0=\frac{\partial \partial \partial}{\partial l}=c^{-\sigma t} e^{-\rho t}-\lambda
$$

which implies that $-\dot{\lambda}=\frac{\partial \mathscr{B}}{\partial \Gamma}=\lambda r$. Differentiating the expression $\sigma^{-\sigma t} e^{-\rho t}=\lambda$ with respect to time and then using the fact that $\lambda / \lambda=-r$, we obtain equation (5) in the texl,

$$
r=\rho+\sigma \frac{\dot{c}}{i}
$$

The level of $c(\cdot)$ is determined by the requirement that the consumer's intertemporal budget constraint be satisfied. It can be verified that after substitution of the equilibrium 
values of $w(t), w_{p}(t)$ and $T(t)$, this forces $C(t)$ to be equal to the aggregate output of consumption goods at each time $t$.

Under balanced growth, the growth rate $g$ is determined by the rate of growth of the total number of inputs, $i^{\text {world }} / \Delta^{\text {world }}$, where $\Delta^{\text {world }}=\Delta+\Lambda^{*}$. From equations $(4 a, b)$ in the text, this is equal to

$$
g=\delta H_{\Delta}+\delta H_{\Lambda}^{*}
$$

Inserting this into the expression for $r$ gives

$$
r=\rho+2 \sigma \delta B_{\mathrm{A}}
$$

In order to solve out for ${ }_{A}$ and hence for $r$, and $g$, one must combine this preference condition with the technological condition in (A.13). Substituting into (A.13) we obtain:

$$
B_{\Delta}=B-B_{Y}=B-\frac{\Lambda}{2 \delta} f(\tau)\left(\rho+2 \sigma \delta H_{A}\right)=\frac{2 \delta H-\Lambda f(\tau) \rho}{2 \delta[1+\Lambda \sigma f(\tau)]}
$$

with $\Lambda$ and $f(\tau)$ defined as in (A.13).

Along a balanced growth path the growth rate in the world and in each country is given by $g=g^{*}=\delta H^{\text {world }}=2 \delta H_{A}$, so

$$
g=\frac{2 \delta H-\Lambda \rho f(\tau)}{1+\Lambda \sigma f(\tau)}
$$

Because $f(0)=1$, this reproduces the formula from Romer (1990b) for the growth rate in a two-country symmetric world economy with $\tau=\tau^{*}=0$. 
In the presence of tariffs, both the amount of $R \& D$ and the growth rate depend negatively on the function $f(\tau)$. This function is equal to 1 when $\tau=0$, increases with $r$ up to a unique maximum, and asymptotically approaches 1 as $\tau$ goes to infinity. This generates the qualitative behavior reproduced in figure 3. This figure plots $g$ as a function of $\tau$ for the following parameter values: $a+\beta=2 / 3, \delta \mathrm{H}=1.4, \rho=.05, \sigma=1$. The value for $\alpha+\beta$ should be equal to the share of manufacturing income that is paid as salaries. Only the product $\delta \mathrm{H}$ is determined in this model, and the value of 0.14 was chosen to make the feasible rates of growth reasonable. Setting $\sigma=1$ corresponds to the choice of logarithmic utility.

\section{A.2 Results from section 5 in the text}

Output of final goods in the home country is given in equation (7) in the text. The profit maximization's problem for given levels of $\|_{Y}$ and $L$ is

$$
\begin{aligned}
\max _{d, m, n} Y\left(L, \mathbb{H}_{Y}, d(\cdot), m(\cdot), n(\cdot)\right)- & \int_{\mathbb{R}_{+}} P_{d^{\prime}}(i) d(i) d i- \\
& \int_{\mathbb{R}_{+}} P_{m}^{*}\left(i^{*}\right) m\left(i^{*}\right) d i *-\int_{\mathbb{R}_{+}} p_{n}(j) n(j) d j .
\end{aligned}
$$

As above, the first order necessary conditions for profit maximization yield the derived demands for $d, m$, and $n$ and symmetrical expressions for $d^{*}, m^{*}$, and $n^{*}$.

Producers of traded durables choose output levels that equate marginal revenue in each location to marginal costs. Since there are no tariffs, producers face the same demand functions locally and abroad when they can sell in both markets. As a result, they will 
charge identical prices in both locations, $P_{d}=P_{m^{*}}=r / 1-a-\beta$. With free trade in final goods and interest rate equalization, symmetric arguments give $P_{d}^{*}=P_{m}^{*}=r / 1-a-\beta$.

The maximization problem for producers of the $j$ goods, which are not traded, is

$$
\max _{n} \pi_{n}=p_{n}(n) n-r n
$$

It can be easily verified that constant marginal costs and a constant elasticity demand imply that $P_{n}=r / 1-a-\beta$ for these goods as well. Consequently, $\bar{d}=\bar{m}^{*}=\bar{n}$, and profit $\pi_{t}$ for traded goods is twice the profit $\pi_{n}$ for the nontraded goods.

Ex ante, a producer of new product does not know whether it will be able to sell its output abroad. When bidding for a new design, the firm calculates the expected profits, which is equal to the probability $1-q$ the good is not subject to foreign protection times $\pi_{t}$, plus the probability $q$ that it is denied access to the foreign market times $\pi_{n}$. (By symmetry, the probabilities of exclusion in the two countries, $q$ and $q^{*}$, are the same.) The price of new designs is equal to the discounted value of expected profits. The price bid for a new patent can then be written as

$$
\begin{aligned}
P_{\Lambda} & =\frac{1}{r}\left[(1-q) \pi_{t}+q \pi_{n}\right] \\
& =\frac{1}{r}(1-q)\left[p\left(\bar{d}+\bar{m}^{*}\right)-r\left(\bar{d}+\bar{m}^{*}\right)\right]+\frac{1}{r} q[p \bar{n}-r \bar{n}] \\
& =\left(\frac{p}{r} 1\right)(1-q)\left(\bar{d}+\bar{m}^{*}\right)+\left(\frac{p}{r} 1\right) q \bar{n} .
\end{aligned}
$$

Then using the result $\frac{p}{r}(1-a-\beta)=1$, the expressions for $p$ in terms of $d, m^{*}$, and $n$ that are derived from the demand curves, and the fact that the quantities chosen by the monopolist are the same, $\bar{d}=\bar{m}^{*}=\bar{n}$, this can be expressed as 


$$
\begin{aligned}
& P_{\Lambda}=\frac{(1-q)(1-a-\beta)}{r}(a+\beta) H_{Y}^{a} L^{\beta}\left(\bar{d}^{1-a-\beta_{+\bar{m}^{*}}}{ }^{1-a-\beta}\right)+\frac{q(1-a-\beta)}{r}(a+\beta) H_{Y}^{a} L^{\beta_{\bar{n}}}{ }^{1-a-\beta} . \\
& =(2-q) \frac{(1-a-\beta)}{r}(a+\beta) H_{Y}^{a} L^{\beta} \bar{d}^{1-a-\beta} .
\end{aligned}
$$

As in the previous section, the result linking the growth rate and the interest rate on the production side follows by equating the return to human capital in the research and manufacturing sectors:

$$
\delta P d^{d^{\text {world }}}=\frac{\partial Y}{\partial H_{Y}}=a H_{Y}^{a-1} L^{\beta}\left[I+I^{*}+J\right] d^{1-a-\beta} .
$$

Inserting the expression from equation (A.20) in for $P_{A}$ in equation (A.21) and solving for $\mathbb{H}_{Y}$, we obtain

$$
A_{Y}=\frac{1}{\delta} \Lambda \frac{1}{2-q} r
$$

where $\Lambda=a /(a+\beta)(1-a-\beta)$ as before.

We solve for the rate of growth as in the tariff example, by using equation (A.14) to express the interest rate in terms of the balanced rate of growth for the economy, $r=\rho+\sigma g$, where $g=\frac{\dot{c}}{c}=\frac{j \text { world }}{A^{\text {world }}}$. Using equation (12) from the text to substitute for $\frac{j^{\text {world }}}{\mathrm{A}^{\text {world }}}$ yields $g=2 \delta H_{N}$ Together these two substitutions give

$$
H_{Y}=\frac{\Lambda}{\delta} \frac{\left[\rho+2 \sigma \delta H_{N}\right]}{2-q}
$$

${ }_{Y}$ can be removed from this expression by using the adding up constraint $H=H_{Y}+H^{+}{ }^{+H}$ 
and the fact that all of the goods that are a vailable for copying are copied, to that

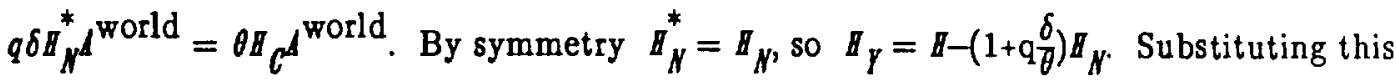
into equation (A.22) and clearing for ${ }_{N}$ yields

$$
Z_{N}=\frac{I-\frac{\Lambda \rho}{\delta(2-q)}}{\frac{2 \Lambda \sigma}{2-q}+q \frac{\delta}{\theta}+1}
$$

Equation (13) in the text then follows from

$$
g=\delta B^{\text {world }}=2 \delta B_{N}
$$

